\title{
SIMULADO DE EVACUAÇÃO EM SITUAÇÃO DE UM INCÊNDIO DE UM EDIFÍCIO ALTO COM FUNÇÕES ADMINISTRATIVAS
}

\section{RESUMO}

\author{
Christa Korzenowski ${ }^{1}$ \\ Jacinto Manuel Antunes de Almeida ${ }^{2}$ \\ Renata Lucena ${ }^{3}$ \\ Roget Kopczynski Rosa ${ }^{4}$ \\ Luiz Carlos Pinto da Silva Filho
}

Como parte das ações realizadas no âmbito do Plano de Prevenção e Combate a Incêndio (PPCl), o Grupo de Trabalho de Prevenção a Incêndios (GTPI) de um determinado edifício alto com funções administrativas no Estado do Rio Grande do Sul realizou um simulado de evacuação em situação de incêndio. Foi estabelecido um cenário hipotético de incêndio no qual se admitiu que o alarme seria acionado primeiramente no $5^{\circ}$ piso, procedendo-se imediatamente à evacuação simultânea de todos os andares. A evacuação foi orientada pelas equipes da Brigada de Incêndio, que conduziram os evacuados até as áreas externas seguras. O exercício foi realizado com aviso prévio dos ocupantes e envolveu diversos órgãos de atendimento e socorro do Município. Observadores do CEPED/RS acompanharam as atividades de coordenação e de evacuação sem interferir no exercício. Observou-se que o simulado foi concluído com êxito e cumpriu os objetivos a que se propunha, contribuindo de forma positiva para a consolidação das competências e procedimentos a adotar em situação de emergência e evacuação. Por outro lado, a anomalia detectada no sistema de alarme de incêndio prejudicou os procedimentos iniciais de evacuação e as falhas encontradas em algumas portas corta fogo podem comprometer a segurança em um incêndio.

Palavras chave: Incêndio; Simulado de Evacuação; Prédio Alto; Edifícios Administrativos.

\footnotetext{
${ }^{1}$ Pós-Doutoranda, PPGEC, Universidade Federal do Rio Grande do Sul, POA/RS. E-mail: ckorzenowski@gmail.com.

${ }^{2}$ Doutorando PPGEC, Universidade Federal do Rio Grande do Sul, POA/RS. E-mail: jasscarnival@gmail.com.

${ }^{3}$ Mestre Eng. Civil, Boa Vista/RR. E-mail: rblucena@gmail.com

${ }^{4}$ Coronel do Corpo de Bombeiros Militar do Rio Grande do Sul, POA/RS. E-mail: roget_k@yahoo.com.br

${ }^{5}$ Professor, Universidade Federal do Rio Grande do Sul, POA/RS. E-mail: Icarlos66@gmail.com
} 


\title{
SIMULATED EVACUATION SITUATION OF A FIRE OF A BUILDING WITH HIGH ADMINISTRATIVE FUNCTIONS
}

\begin{abstract}
As part of the actions taken under the Prevention and Fire Fighting Plan, the Working Group for the Prevention of Fires of a certain high building with administrative functions in Rio Grande do Sul conducted a simulated fire evacuation. A hypothetical scenario of fire was established in which it was admitted that the alarm was first triggered on the 5th floor, proceeding immediately to the simultaneous evacuation of all floors. The evacuation was guided by the teams of the Fire Brigade, which led the evacuees to the safe outdoors. The exercise was conducted with notice of the occupants and involved various organs of care and help of the Municipality. Independent observers of CEPED / RS followed the coordination and evacuation activities without interfering in the exercise. It was observed that the simulated was successful and fulfilled the objectives for which they were proposed, contributing positively to the consolidation of skills and procedures to adopt in emergency and evacuation situations. On the other hand, the anomaly detected in the fire alarm system undermined the initial evacuation procedures and flaws found in some fire doors can compromise safety in case of fire.
\end{abstract}

Keywords: simulated, fire, evacuation, high building.

Artigo recebido em 05/12/16 e Aceito em 09/01/17. 


\section{INTRODUÇÃO}

A implementação de medidas de segurança contra incêndio em edifícios apresenta diversos desafios relacionados às características construtivas, à ocupação e à gestão da edificação. O principal objetivo da Segurança Contra Incêndio em Edificações (SCIE) é garantir a segurança dos ocupantes na evacuação em caso de incêndio (BRENTANO, 2015).

A segurança depende da boa concepção do projeto de proteção e prevenção contra incêndio, a fim de permitir a rápida desocupação dos ambientes atingidos e ameaçados pelas chamas (SILVA et. al., 2008).

Por se tratarem de edifícios com um grande número de ocupantes, altura elevada e ocorrência simultânea de serviços distintos, a segurança contra incêndio em edifícios administrativos altos exige medidas de segurança mais complexas do que em edifícios comuns. Por outro lado, nas edificações que possuam plano de emergência interno devem ser realizados periodicamente exercícios para testar o referido plano e treinar os ocupantes, assim como para aperfeiçoar os procedimentos inerentes, com destaque para a organização direcionada para situações de emergência, de forma a criar rotinas comportamentais e de atuação (PINHEIRO, 2012).

No planejamento da evacuação de um edifício devem ser garantidos diversos critérios de segurança, por exemplo: a existência de saídas, em número e largura suficientes, convenientemente distribuídas e devidamente sinalizadas; as vias de evacuação devem ter largura adequada e, quando necessário, ser protegidas contra o fogo, o fumo e os gases de combustão; as distâncias a percorrer devem ser limitadas; em determinados casos, a evacuação pode processar-se para espaços temporariamente seguros, denominados de zonas de refúgio. 
Dentro do âmbito do Plano de Prevenção e Combate à Incêndio (PPCl) de um determinado prédio administrativo, elaborado de acordo com a Lei Complementar 14.376 do Estado do Rio Grande do Sul (2013), o Grupo de Trabalho de Prevenção a Incêndios (GTPI) realizou um simulado de evacuação do edifício. O Centro Universitário de Estudos e Pesquisas sobre Desastres da Universidade Federal do Rio Grande do Sul (CEPED/RS) foi convidado a atuar como observador, de forma a contribuir para a análise do exercício de simulação. Para acompanhar e observar o desenvolvimento do simulado, o CEPED/RS constituiu uma equipe de pesquisadores e profissionais, com competências nas áreas de incêndio e desastres, que atuavam no $1^{\circ}$ Comando Regional de Bombeiros de Porto Alegre. Os observadores acompanharam as atividades, sem interferir.

Este trabalho teve como objetivo principal analisar as informações coletadas durante o simulado para proceder às recomendações necessárias no sentido de contribuir para a melhoria dos procedimentos a adotar em caso de evacuação, visando o aumento do nível de segurança do edifício em termos de SCIE.

\section{CONSIDERAÇÕES GERAIS SOBRE SIMULADOS DE EVACUAÇÃO DE EDIFÍCIOS}

Um simulado é "a representação de uma resposta a uma emergência provocada por um ou mais fenômenos ou agentes perturbadores", e durante o exercício devem simular-se diversos cenários, tão próximos quanto possível da realidade, com a finalidade de testar e preparar a resposta mais eficaz perante eventuais situações reais de perturbação. Por outro lado, os simulados têm como finalidade incrementar nos utilizadores, a confiança na sua capacidade de resposta para preservar a vida e enfrentar as situações psicológicas negativas como o pânico. (PINHEIRO, 2012) 
Revista Científica do Corpo de Bombeiros Militar de Pernambuco

Seção 1 - Artigos Técnico Científicos

Artigo publicado no Vol.03 №06 - Edição de JAN a JUN 2017 - ISSN 2359-4829

Versão on-line disponível em: http://www.revistaflammae.com

Normalmente, os simulados de evacuação tentam recrear situações de perigo através de cenários que não reproduzem todas as condições que podem ocorrer no decurso de um incêndio, tais como o stress e a tensão inerente a uma situação de emergência. Para um dos principais motivos assenta nos perigos inerentes a uma recriação mais realista, que poderia provocar danos físicos e humanos. Além disso, os meios financeiros e temporais necessários para simular cenários mais complexos, mais próximos à realidade, seriam extremamente elevados. (AVERILL \& MILETI, 2005)

De acordo com Almeida (ALMEIDA, 2013), os objetivos a atingir com o estudo do comportamento humano em situações normais e de emergência na evacuação de edifícios passam por:

a) Calcular o tempo máximo de evacuação de um edifício;

b) Aferir e validar as regras de segurança das arquiteturas dos edifícios;

c) Definir estratégias para os técnicos que elaboram Planos de Emergência e Evacuação.

Para se atingir estes objetivos, é necessário, entre outros:

a) Identificar os locais onde possa ocorrer congestionamento de pessoas;

b) Validar o dimensionamento e localização das vias de evacuação, horizontais e verticais;

c) Identificar os aspetos mais importantes na movimentação de pessoas, em situações normais e de emergência;

d) Caracterizar os parâmetros que afetam a mobilidade de pessoas (físicos, psicológicos, sociológicos);

e) Identificar as limitações para pessoas de mobilidade reduzida e apontar soluções;

f) Perceber o comportamento humano e os mecanismos de tomada de decisão, para elaborar estratégias adequadas que permitam acelerar 0 processo de evacuação; 
g) Definir medidas de segurança passiva e ativa com impacto positivo na evacuação.

Os simulados de evacuação de edifícios envolvem diversos fatores importantes e deve ser dado especial enfoque ao funcionamento dos sistemas de detecção e alarme - incluindo a reação dos ocupantes, o nível sonoro do alarme e a transmissão de mensagens (comunicação) - e à visibilidade durante a evacuação - sinalização e rotas de fuga, velocidade de deslocação e instabilidade emocional. (COELHO, 2007)

\section{SIMULADO DE EVACUAÇÃO - CASO PRÁTICO}

Para a análise do simulado de evacuação, os observadores do CEPED/RS foram convidados a assistir à última reunião que antecedeu o exercício, realizada pelo GTPI do edifício. No decorrer do simulado, o grupo de observadores se dividiu em três zonas de ação distintas- evacuação pela rota de fuga, sala de vídeo monitoramento e exterior do edifício (incluindo zona quente e pontos de encontro). A análise aqui apresentada aborda os seguintes itens:

a) Planejamento e organização do simulado;

b) Evacuação do edifício;

c) Papel dos observadores;

d) Atuação da coordenação;

e) Atuação da brigada de incêndio;

f) Atuação dos participantes;

g) Falhas e anomalias nos equipamentos. 


\subsection{Validade do exercício}

Os exercícios de simulação apesar de não representarem a realidade de um desastre, são ferramentas fundamentais para a capacitação das equipes de intervenção, bem como para o aumento da percepção de risco dos ocupantes em situação de vulnerabilidade, para que num cenário real se reduzam eventuais danos humanos e materiais associados a eventos adversos.

Nesse sentido, o simulado foi uma oportunidade significativa para agregar e promover a mobilização nas ações de prevenção e evacuação e consolidar competências da Brigada de Incêndio e dos ocupantes que participaram no exercício.

\subsection{Planejamento e Organização}

A NBR 15219 estabelece "os requisitos mínimos para a elaboração, implantação, manutenção e revisão de um plano de emergência contra incêndio, visando proteger a vida e o patrimônio, bem como reduzir as consequências sociais do sinistro e os danos ao meio ambiente". Neste plano devem ser definidos diversos itens entre os quais, saídas de emergência, sinalização de segurança, brigada de incêndio, rotas de fuga e pontos de encontro. O plano de emergência contra incêndio foi elaborado por escrito pela equipe responsável pela coordenação da brigada de incêndio considerando-se os seguintes aspectos: localização, construção, ocupação, população, característica de funcionamento, pessoas portadoras de deficiências, outros riscos inerentes à atividade e recursos humanos disponíveis. (ABNT, 2005)

Em edifícios altos é comum se optar pela evacuação parcial do edifício, que pode ser ou não faseada. Neste tipo de edifícios, a segurança e rapidez na 
evacuação de pessoas com limitações físicas constitui um desafio. Quando ocorre um incêndio em áreas remotas do edifício, poderá ser mais seguro para os ocupantes de áreas não afetadas permanecerem no local para aguardar novas instruções.

Para fins do simulado, estabeleceu-se um cenário hipotético de incêndio, no qual se admitiu que 0 alarme fosse acionado primeiramente no $5^{\circ}$ piso, procedendo-se imediatamente à evacuação dos ocupantes do edifício.

Este foi o primeiro grande simulado realizado no edifício, por isso, a coordenação optou por um cenário mais geral, organizando a evacuação total e simultânea dos 21 andares do edifício através das escadas enclausuradas à prova de fogo e fumaça. Foram previstas 2 saídas para o exterior, uma para cada ala (ala norte e ala sul), e organizados 2 pontos de encontro no exterior.

O abandono seria iniciado conforme comunicação da brigada, conduzindo a população fixa e flutuante para os pontos de encontro, ali permanecendo até a definição final da emergência. $O$ apoio externo, como Corpo de Bombeiros e SAMU, seria acionado simultaneamente ao início do exercício pela brigada de incêndio, o que está em conformidade com a NBR 15219. (ABNT, 2005)

A manutenção do plano de emergência foi feita com base na norma brasileira, através de reuniões com o coordenador geral da brigada de incêndio e os chefes da brigada de incêndio, com registro em ata. Foram realizadas diversas reuniões ordinárias, sempre que possível, mensais, para discutir o calendário dos exercícios de abandono, as funções de cada pessoa dentro do plano de emergência contra incêndio, as condições de uso dos equipamentos de combate a incêndio e apresentação dos problemas relacionados à prevenção de incêndios, encontrados nas inspeções, entre outros itens.

Através da informação disponibilizada, foi possível observar que, dentro do âmbito do plano de emergência contra incêndio, de forma geral, o exercício 
mostrou estar bem organizado, tendo um cenário claramente definido e um roteiro detalhado, especialmente nas áreas internas do edifício.

Por outro lado, o planejamento das áreas externas deveria ter sido mais rigoroso, prevendo o isolamento da zona destinada à triagem das vítimas (zona quente). Isto contribuiria para facilitar as ações de socorro e minimizar a possibilidade de ocorrência de incidentes numa situação real.

Além disso, teria sido importante incluir no planejamento do exercício o regresso ao edifício, após a verificação da segurança.

\subsection{Papel dos Observadores}

A presença de observadores externos é considerada um subsídio importante para que se possa avaliar e registrar o desenvolvimento e os resultados de cada simulado. Foi liberado o acesso dos observadores a todos os pontos do exercício.

A visita ao local, antes do exercício por ocasião da reunião de preparação do simulado, foi importante para o planejamento das atividades dos observadores. No entanto, a observação do exercício ficou limitada pela falta de acesso a informações mais detalhadas relativas ao planejamento do exercício. Seria importante sistematizar e disponibilizar digitalmente todo o material pertinente e providenciar cópias do roteiro a ser seguido. Além disso, seria desejável ter acesso às planilhas de controle preenchidas durante 0 exercício, para análise estatística de resultados.

\subsection{Evacuação do Edifício}

A evacuação do edifício decorreu de acordo com o estabelecido no plano, sem registro de maiores incidentes. De acordo com os dados divulgados, foram evacuados 1229 ocupantes, sendo a maior parte população fixa composta por 
servidores do edifício. Logo após o soar do alarme, os líderes e cerra-filas, divididos por alas e por andares e já posicionados para o abandono do edifício, orientaram a evacuação dos ocupantes através das escadas enclausuradas. $O$ tempo efetivo de evacuação foi de 25 minutos. Este tempo equivale ao tempo real de deslocamento, já que os tempos de detecção e de reação foram nulos.

O tempo evacuação foi inferior ao tempo de resistência ao fogo das escadas enclausuradas que, de acordo com o PPCl do edifício, é de 4 horas, se os sistemas de proteção passiva funcionarem adequadamente. Por outro lado, de acordo com a literatura especializada, tempos de evacuação superiores a 5 minutos devem ser considerados como tempos que precisam ser melhorados. Isto poderia ser conseguido aumentando o número de rotas de fuga e através da criação de zonas de refúgio dentro do edifício.

Durante a evacuação, foram registradas algumas perturbações no fluxo da descida, destacando-se dois congestionamentos nas escadas, de 3 minutos e de 5 minutos, respectivamente, no $16^{\circ}$ andar e no $14^{\circ}$ andar, cujas causas ficaram por esclarecer.

No exterior do edifício também foram detectados alguns problemas, dos quais se destaca a entrada de um número significativo de pessoas, incluindo participantes e imprensa, no interior da zona quente.

Houve também alguma dificuldade em identificar nos postos de controle os brigadistas de apoio responsáveis pela contagem do exercício, uma vez que os coletes que identificavam as diferentes equipes eram muito idênticos (mesma cor e formato).

\subsection{Atuação da Coordenação}

Em situações em que o roteiro de simulação faz parte de um plano integrado, suficientemente detalhado e de amplo conhecimento por parte dos 
envolvidos, geralmente os intervenientes assimilam as suas responsabilidades e assumem naturalmente as suas funções, dispensando uma coordenação mais centralizada.

No entanto, sabe-se que esta conscientização de procedimentos de segurança é um processo complexo e demorado de se implementar. Um cenário simplificado é distinto de um desastre real, onde as incertezas demandam maior esforço por parte da coordenação das equipes.

Antes, durante e após o exercício a coordenação cumpriu as suas funções, assumindo as suas responsabilidades, garantindo a segurança de todos os ocupantes durante a evacuação e garantindo a segurança do edifício antes do regresso, cooperando com outros oficiais de emergência e assessorando as unidades de serviço de emergência, quando necessário. Por outro lado, seria desejável um maior isolamento do exercício, em especial, no que se refere à comunicação com a imprensa, que decorreu quase em simultâneo com as atividades simuladas no exterior do edifício.

\subsection{Atuação da Brigada de Incêndio}

A NBR 14276 (ABNT, 2006), define brigada de incêndio como "Grupo organizado de pessoas preferencialmente voluntárias ou indicadas, treinadas e capacitadas para atuar na prevenção e no combate ao princípio de incêndio, abandono de área e primeiros socorros, dentro de uma área preestabelecida na planta". Uma evacuação de emergência efetiva requer que os elementos da brigada de incêndio estejam cientes das suas funções e responsabilidades. Os elementos da brigada de incêndio devem ser responsáveis por:

a) Estar familiarizados e seguir os procedimentos de evacuação de acordo com o plano de operações e evacuação de emergência;

b) Participar em exercícios e treinamento, conforme necessário;

c) Informar a coordenação em caso de ausência; 
d) Orientar os colegas nos procedimentos de evacuação de emergência;

e) Orientar os visitantes não familiarizados com os procedimentos adequados durante uma evacuação de emergência;

f) Garantir que ninguém fique para trás ou retorne ao edifício;

g) Ajudar os ocupantes que estão com dificuldades.

Os brigadistas do CAFF foram selecionados atendendo aos critérios da norma brasileira, descritos a seguir:

a) Permanecer na edificação durante seu turno de trabalho;

b) Possuir boa condição física e boa saúde;

c) Possuir bom conhecimento das instalações;

d) Ter mais de 18 anos;

e) Ser alfabetizado.

No exercício de evacuação foram colocados 2 brigadistas em cada uma das duas alas por pavimento, independentemente da população fixa do pavimento. De acordo com a norma brasileira, para este tipo de edifício com grau de risco de incêndio médio, para cada pavimento com população fixa de até 10 pessoas teria que haver pelo menos 4 brigadistas e quando a população fixa de um pavimento, compartimento ou setor for maior que 10 pessoas teria que ser colocado mais 1 brigadista para cada grupo adicional de até 15 pessoas. A distribuição de brigadistas não seguiu a recomendação da norma brasileira; no exercício participaram apenas 90 brigadistas, o que corresponde apenas a $60 \%$ do total do efetivo disponível.

A comunicação interna e externa foi feita através de celulares pessoais, uma vez que não foram disponibilizados rádios.

De forma geral, os líderes e cerra-filas participantes cumpriram as suas competências na evacuação do edifício até aos pontos de encontro. No entanto, no piso térreo houve alguma falta de orientação mais ativa por parte dos brigadistas na organização do fluxo, já que as vítimas fictícias ficaram inicialmente desassistidas. 
No exterior, constatou-se o desencontro entre os primeiros ocupantes evacuados e os responsáveis pela contagem nos postos de controle. No entanto, a contagem do exercício não foi comprometida.

Dentro deste contexto, deve ser promovida uma maior conscientização junto dos brigadistas que faltaram ao exercício e deve ser reforçada a responsabilidade dos brigadistas enquanto orientadores e disciplinadores durante todo o exercício de evacuação. Os futuros exercícios servirão, também, para consolidar a relação de confiança entre brigadistas e colegas servidores.

\subsection{Atuação dos participantes}

Em situação de emergência as orientações básicas aos ocupantes de um edifício são: ao escutar o toque de alarme, devem alertar os seus colegas e abandonar o edifício, usando a rota de fuga mais próxima; o regresso ao edifício deve ser feito somente após o edifício ser declarado seguro e deve decorrer de forma ordenada.

Os 1229 ocupantes evacuados corresponde a menos de um terço do total de servidores, que diariamente ocupam o edifício. A maioria dos participantes mostrou estar consciente dos procedimentos de evacuação no interior do edifício, procedendo à evacuação organizada, seguindo as instruções dos colegas brigadistas. Algumas vezes a seriedade que habitualmente é exigida num exercício de simulação foi perturbada por algumas pequenas brincadeiras. Em alguns casos, a brincadeira não terá constituído uma perturbação em si, e terá sido um recurso para contornar uma situação potencial de pânico.

Quanto ao comportamento no exterior, a dispersão dos participantes para a zona quente após a concentração nos pontos de encontro, reflete não só a curiosidade, como também alguma falta de sistematização dos procedimentos de emergência e evacuação. Esta dispersão poderá ser evitada através da 
comunicação de instruções mais claras quanto ao procedimento de abandono do local, complementada por um isolamento mais adequado da área quente.

Além disso, o não comparecimento de um número significativo de servidores no exercício de simulação, em parte, por se tratar de um simulado com aviso prévio e tolerância de falta, evidencia uma necessidade de maior conscientização para a participação em ações de prevenção.

\subsection{Falhas e Anomalias nos Equipamentos}

Foram constatadas algumas falhas e anomalias nos equipamentos, que num cenário real de incêndio poderão comprometer a segurança dos ocupantes, as quais se destacam a seguir:

- O sistema de alarme do edifício apresentou problemas, especificamente, retardo no disparo inicial e baixo volume do som, sendo inaudível em alguns pontos do edifício.

- O sistema de vídeo monitoramento foi prejudicado por queda da rede, sendo restabelecido antes do início do exercício.

- Não existe corrimão do lado direito das escadas enclausuradas, dificultando o fluxo de evacuação.

- Foram detectadas diversas falhas nas portas corta-fogo, nomeadamente, projeto inadequado, ausência de trincos em algumas portas e presença de frestas que comprometem a estanqueidade do sistema.

- A brigada de incêndio não possui sistema de comunicação via rádio. Foi necessário recorrer aos equipamentos pessoais (celulares) para estabelecer a comunicação entre os brigadistas durante o exercício. 
Revista Científica do Corpo de Bombeiros Militar de Pernambuco

Seção 1 - Artigos Técnico Científicos

Artigo publicado no Vol.03 №06 - Edição de JAN a JUN 2017 - ISSN 2359-4829

Versão on-line disponível em: http://www.revistaflammae.com

\subsection{Atuação das equipes de atendimento às vítimas}

$\mathrm{O}$ atendimento às vítimas foi prestado pelo Corpo de Bombeiros e pelo SAMU. As equipes de atendimento às vítimas mostraram estar motivadas e envolvidas nas ações de socorro, sendo rápidas na chegada ao local; se empenharam no apoio à evacuação e foram eficazes nas ações de socorro às vítimas simuladas isoladas na área quente, no exterior do edifício. No entanto, este isolamento nem sempre funcionou, ocasionando alguma desorganização nesta zona.

\subsection{Imagens do Simulado}

Neste item se apresenta 0 registro fotográfico realizado pelos observadores do CEPED-RS, do simulado.

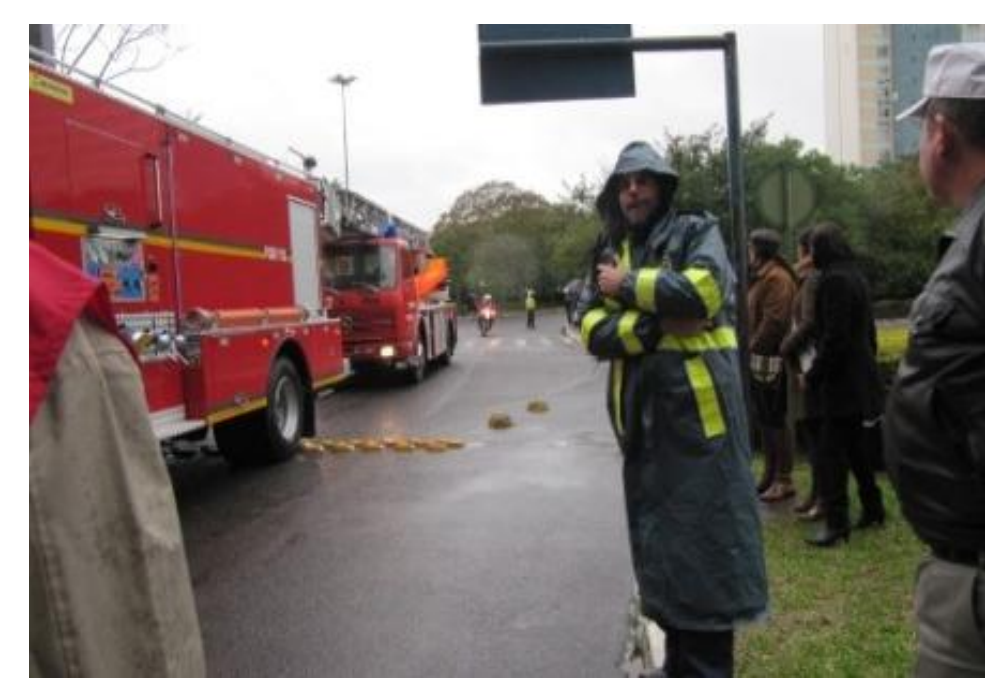

Figura 1 - Chegada do Corpo de Bombeiros ao local. 


\section{Revista FLAMMAE}

Revista Científica do Corpo de Bombeiros Militar de Pernambuco

Seção 1 - Artigos Técnico Científicos

Artigo publicado no Vol.03 №06 - Edição de JAN a JUN 2017 - ISSN 2359-4829

Versão on-line disponível em: http://www.revistaflammae.com

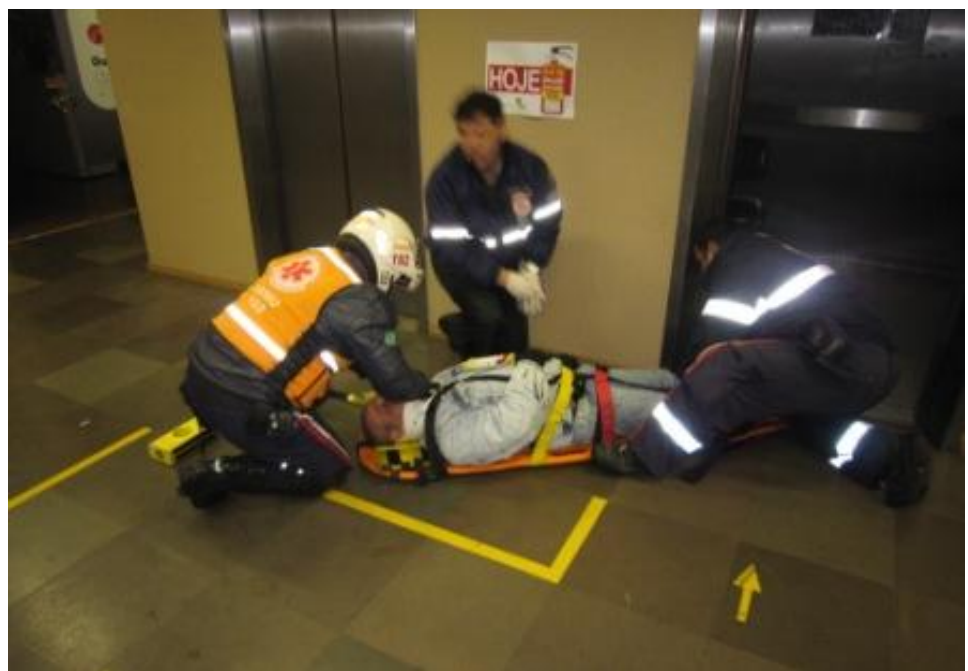

Figura 2 - Atendimento às vítimas fictícias no interior do edifício.

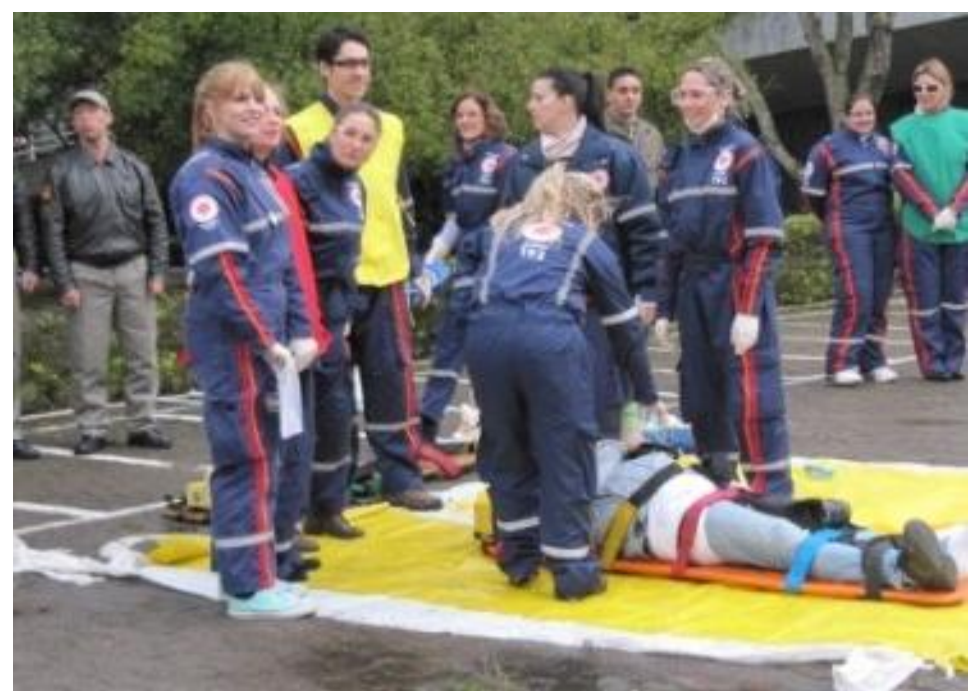

Figura 3 - Atendimento realizado pelo SAMU na zona quente no exterior. 


\section{Revista FLAMMAE}

Revista Científica do Corpo de Bombeiros Militar de Pernambuco

Seção 1 - Artigos Técnico Científicos

Artigo publicado no Vol.03 №06 - Edição de JAN a JUN 2017 - ISSN 2359-4829

Versão on-line disponível em: http://www.revistaflammae.com

Figura 4 - Corpo de Bombeiros em atendimento às vítimas fictícias.

\section{RECOMENDAÇÕES}

As recomendações apresentadas a seguir visam contribuir para que alguns procedimentos possam ser melhorados.

a. Realizar anualmente simulados com cenários diferenciados;

b. Aplicar outras técnicas para a gestão da evacuação (modelos teóricos e modelagem computacional).

c. Reforçar a organização das áreas exteriores;

d. Incluir no planejamento o retorno ao edifício;

e. Planejar a evacuação parcial e/ou faseada do edifício.

f. Reforçar a divulgação do plano de emergência e de evacuação entre os ocupantes, por meio digital e físico (plantas de emergência e manuais simplificados de instruções);

g. Proceder à identificação diferenciada entre os elementos da brigada de incêndio, utilizando coletes e capacetes com cores distintas;

h. Providenciar maior visibilidade dos postos de controle no exterior;

i. Impedir, através de cordões de isolamento, o acesso de pessoas não autorizadas às áreas destinadas para triagem de vítimas (zona quente); 
j. Reforçar os meios de comunicação entre equipes e o canal de comunicação entre os elementos da brigada e a coordenação;

k. Adequar os sistemas de proteção contra incêndio, com enfoque na adequação das portas corta-fogo de acordo com as exigências de projeto da NBR 11742, de forma a garantir a estanqueidade ao fogo e fumaça das escadas enclausuradas;

I. Melhorar a sinalização nas rotas de fuga.

\section{CONCLUSÕES}

Considerando as observações realizadas, é possível afirmar que o simulado foi realizado com êxito, seguindo as principais recomendações das normas brasileiras, cumprindo os objetivos a que se propunha e contribuindo de forma positiva para a consolidação das competências e procedimentos a adotar em situação de emergência e evacuação.

Os participantes e as equipes responsáveis pela coordenação, orientação e atendimento se mostraram empenhados no exercício, consolidando competências e destacando as oportunidades de aprendizado proporcionadas.

Para a construção de modelos comportamentais que permitam agir de forma sistematizada em situação de emergência, é fundamental investir na realização de mais exercícios de simulação, em condições diferenciadas, aumentando gradualmente o nível de incerteza envolvido.

Por último, é fundamental garantir a manutenção do plano de emergência contra incêndio, garantindo o pleno funcionamento dos sistemas de proteção contra incêndio, eliminando as anomalias e falhas detectadas, para que a evacuação segura dos ocupantes não seja comprometida em caso de ocorrência de incêndio. 


\section{REFERÊNCIAS}

ALMEIDA, J. E. S. C. Modelação e simulação do comportamento humano na evacuação de edifícios. NFPA-APSEI Fire \& Security, Estoril, Dezembro, 2013.

ASSOCIAÇÃO BRASILEIRA DE NORMAS TÉCNICAS. NBR 9077: Saídas de emergência em edifícios. Rio de Janeiro, ABNT, 2001.

. NBR 11742: Porta corta-fogo para saída de emergência. Rio de Janeiro, ABNT, 2003.

NBR 14276: Brigada de incêndio - Requisitos. Rio de Janeiro, ABNT, 2006.

NBR 15219: Plano de emergência contra incêndio - Requisitos. Rio de Janeiro, ABNT, 2005.

AVERILL, J. D.; MILETI, D. S. World Trade Center disaster occupant behavior, egress, and emergency communications. No. NIST NCSTAR 17, WTC Investigation, Setembro, 2005.

BRENTANO, T. A proteção contra incêndios no projeto de edificações. Ed.: Edição de autor, 3ª edição, Porto Alegre, RS, 2015.

COELHO, A. L. Modelação matemática da evacuação de edifícios sujeitos à ação de um incêndio. Tese (Doutorado em Engenharia de Civil), Faculdade de Engenharia da Universidade do Porto, Porto, 2007.

LEI COMPLEMENTAR 14.376. Normas sobre segurança, prevenção e proteção contra incêndios nas edificações e áreas de risco de incêndio no Estado do Rio Grande do Sul. Porto Alegre, RS, 2013.

PINHEIRO, J. Medidas de autoproteção de segurança contra incêndio em edifícios. Volume I - Organização geral. Ed.: Autoridade Nacional de Proteção Civil, ANPC, Lisboa, 2012.

SILVA, V. P. ; PANNONI, F. D. ; PINTO, E. M.; SILVA, A. A. Segurança das estruturas em situação de incêndio. In: $A$ segurança contra incêndio no Brasil. Cap. X -. Ed.: Projeto Editora, São Paulo, 2008. 